\title{
Right Malignant Cerebral Infarct Following Mild Head Trauma in a Healthy Child. Case Report
}

\section{Andrea Ortiz-Ordoñez ${ }^{1 *}$, Rodríguez-Cajiao Felipe ${ }^{1}$ and Acosta- Quintana, Leonardo ${ }^{2}$}

${ }^{1}$ Neurosurgery Resident, Universidad San Francisco de Quito USFQ, Colegio de Ciencias de la Salud, Calle Diego de Robles s/n y Pampite, Quito, Ecuador

${ }^{2}$ Neurosurgeon at Neurosurgery Department, Carlos Andrade Marín Hospital, Ecuador *Corresponding Author: Andrea Ortiz-Ordoñez, Universidad San Francisco de Quito USFQ, Colegio de Ciencias de la Salud, Calle Diego de Robles s/n y Pampite, Quito, Ecuador.
Received: May 11, 2020

Published: May 18, 2020

(C) All rights are reserved by Andrea

Ortiz-Ordoñez., et al.

\begin{abstract}
Introduction: Mild head trauma is common in childhood; however, post-traumatic stroke is extremely rare and risk factors are identified in most cases.

Case Report: A 3-year-old male presenting headache, drowsiness, irritability, and left upper limb weakness was admitted after 72 hours of mild head trauma. Imaging showed malignant infarction of right middle cerebral artery and decompressive hemicraniectomy was performed achieving gradual neurological recovery.

Discussion: The intracranial vessel anatomy changes from prenatal life to adulthood, which could predispose to post-traumatic ischemic stroke. This is the first case reporting posttraumatic malignant cerebral infarct in a healthy child due to minor head trauma. Conclusion: Post-traumatic ischemic stroke in children has been described in the literature, but the pathogenesis remains unclear. The ischemia pattern, the trauma time relation, and the exclusion of other stroke causes, such as arterial dissection and cardio-embolism, lead us to conclude that this association is not coincidental.
\end{abstract}

Keywords: Mild Head Trauma; Children; Stroke; Malignant Cerebral Infarct; Decompressive Craniectomy

\section{Abbreviation}

GCS: Glasgow Coma Scale; MRI: Magnetic Resonance Imaging; ICP: Intracranial Pressure; PICU: Pediatric Intensive Care Unit; CT: Computerized Tomography; FLAIR: Fluid-attenuated inversion recovery; ICA: Internal Carotid Artery; MCA: Middle Cerebral Artery; STA: Superficial Temporally Artery; CMV: Cytomegalovirus; IL: interleukin; DHL: Dehydrogenase Lactate

\section{Introduction}

Minor head injuries are common accidents in childhood and they often present with normal neurological findings [1-3]. Stroke is relatively infrequent in children and posttraumatic ischemia is a rarely described event $[1,2,4]$. Previously reported cases mostly describe basal ganglia infarct [1-4]. The authors present the first case of posttraumatic malignant infarct in a healthy child after a mild head trauma managed with decompressive hemicraniectomy.

Ischemic stroke can lead to significant morbidity and mortality and can occur at any age. The incidence is higher in children under 2 years old and decreases progressively until adolescence $[1,4,5]$. The calculated annual ischemic stroke rate within the pediatric population ( 1 month to 12 years) is around $5-33 / 100,000$ [58]; further investigation, generally reveals associated risk factors; however, a small group remains unidentified $[5,8,9]$. The reasons why this entity appears to be confined to young children are not clear; however, the anatomical relationship of brain vessels during childhood might play a crucial role. Posttraumatic stroke's frequency, cause, and influence on mortality are not well elucidated $[1,5]$.

\section{Case Report}

A 3-year-old male was admitted to our emergency room after 72 hours of a head-on fall from a height of $40 \mathrm{~cm}$. The child did not lose consciousness nor have seizures or other previous medical conditions. Initial brain Computerized Tomography (CT) was normal. Headache, drowsiness, and left upper limb weakness were gradually developed. Upon admittance, involuntary left face muscle contractions accompanied by nausea and vomiting were followed by progressive sleepiness and irritability: Glasgow Coma Scale (GCS) was $11 / 15$ (M5, V3, 04). There was a muscle strength of $3 / 5$ in the 
left upper extremity and 4/5 in the left lower extremity. Brain Fluid-attenuated inversion recovery (FLAIR) Magnetic Resonance Imaging (MRI) demonstrated a high-signal intensity area in the right middle cerebral artery territory (involving $2 / 3$ of its territory), diffusion-weighted and diffusion-weighted ADC mapping images confirmed malignant ischemic injury (Figure 1). Cervical MRI was normal (Figure 2).

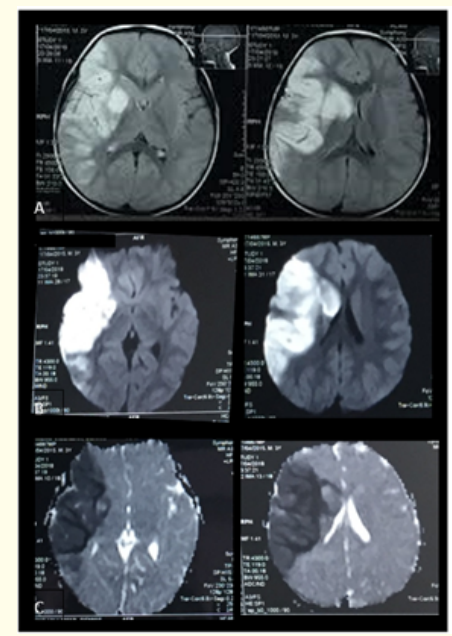

Figure 1: Brain MRI compatible with right malignant infarct with perilesional edema and no midline shift. A: FLAIR; B:

Diffusion-weighted sequence. C: Diffusion-weighted ADC mapping image.

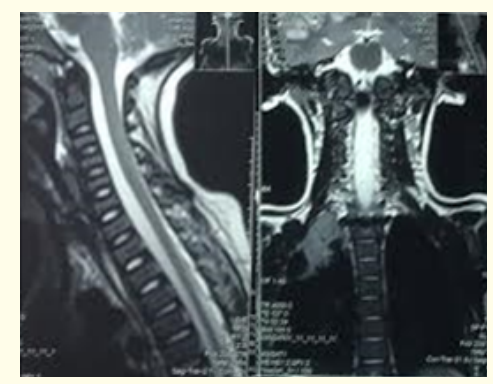

Figure 2: Cervical spine MRI showing normal findings.

Primary right decompressive hemicraniectomy was performed 72 hours after trauma and 24 hours after the symptoms started. Edematous cortex was found but, no herniation was seen in surgery. Immediate post-surgical intracranial pressure (ICP) was 12.5 mmHg it dropped to $8.5 \mathrm{mmHg}$ after 72 hours in the Pediatric Intensive Care Unit (PICU) (Figure 3). Seizures were medically controlled. Vasopressor support was removed after 72 hours and he was successfully extubated on day 6 (Figure 4). Acetylsalicylic acid was started.

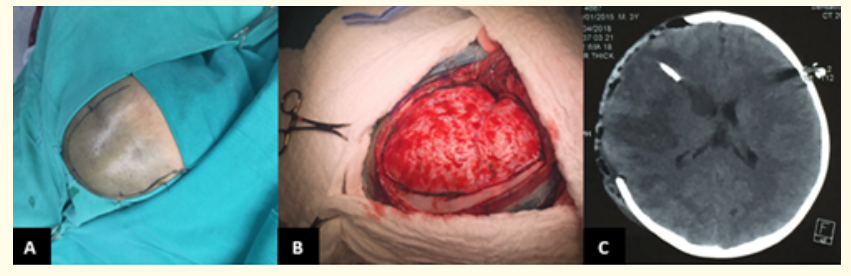

Figure 3: Right decompressive craniectomy. A: Patient positioning. B: Edematous cortex after dural opening. C: Postsurgical Brain CT scan showing right frontal intraventricular ICP monitor catheter.

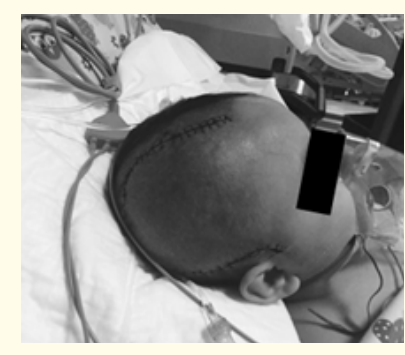

Figure 4: Patient on day 6 after trauma with good wound healing.

During his hospitalization, a complete hematological workup (Table 1) excluded the possibility of pro-thrombotic predisposition: normal blood cell count, platelet count with peripheral blood smear examination, erythrocyte sedimentation rate, viral panel, liver function test, lipid profile, and, T3, T4 and TSH levels. The autoimmune panel was also normal. To rule out the embolic cause of the infarct, echocardiography and carotid Doppler examination were also performed with normal findings.

Angio-MRI (Figure 5) on day 12 failed to demonstrate either obliteration or stenosis of the cerebral arteries and venous. Unluckily, parents did not authorize angiography, so it was not possible to define vasospasm vs thrombi. The patient evolved satisfactorily and was discharged at post-trauma day 15 with GCS 15/15 and muscle strength of $1 / 5$ in the left upper limb and $3 / 5$ in the lower left limb.

At 3 months follow up, an early cranioplasty was performed. His hemiparesis improved gradually. At 6 months follow-up patient showed only mild lower limb weakness $(4 / 5)$ and he was able to walk without assistance. Cranioplasty was removed due to material exposure through the skin. A follow-up examination 12 months after discharge documented complete resolution of the neurologic deficits. He is still under epilepsy treatment, neuropsychological follow up and he is attending regular school (Figure 6). 


\begin{tabular}{|c|c|c|c|c|c|}
\hline \multirow{2}{*}{ 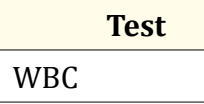 } & \multicolumn{2}{|c|}{ Result } & \multirow{2}{*}{$\frac{\text { Test }}{\text { Beta2 microglobulin }}$} & \multicolumn{2}{|c|}{ Result } \\
\hline & 6.53 & $10^{\wedge} 3 / \mathrm{uL}$ & & 988 & $\mathrm{ng} / \mathrm{ml}$ \\
\hline Hemoglobin & 12.0 & $\mathrm{~g} / \mathrm{L}$ & Anti-nuclear antibody & 0.22 & $\mathrm{ng} / \mathrm{ml}$ \\
\hline Hematocrit & 36.5 & $\%$ & anti-Ds DNA & 0.01 & $\mathrm{U} / \mathrm{ml}$ \\
\hline Platelets & 271 & $10^{\wedge} 3 / \mathrm{uL}$ & ACS anti-SM-RNP & 2.8 & $\mathrm{U} / \mathrm{ml}$ \\
\hline Sodium & 140 & $\mathrm{mEq} / \mathrm{L}$ & Anti-SSA (Ro) & 2.1 & $\mathrm{U} / \mathrm{ml}$ \\
\hline Potassium & 4.8 & $\mathrm{mEq} / \mathrm{L}$ & Anti-SSB (La) & 1.4 & $\mathrm{U} / \mathrm{ml}$ \\
\hline iCa (serum) & 1.1 & $\mathrm{mEq} / \mathrm{L}$ & ACS anti-ANCA PR3 & 1.5 & $\mathrm{U} / \mathrm{ml}$ \\
\hline tCa (serum) & 9.9 & $\mathrm{mEq} / \mathrm{L}$ & ACS anti-ANCA MPO & 1.3 & $\mathrm{U} / \mathrm{ml}$ \\
\hline Phosphorus & 4.6 & $\mathrm{mEq} / \mathrm{L}$ & anti- cardiolipin IgG & 2.2 & $\mathrm{U} / \mathrm{ml}$ \\
\hline \multirow[t]{2}{*}{ Magnesium } & 2.87 & $\mathrm{mEq} / \mathrm{L}$ & anti-cardiolipin IgM & 0.3 & $\mathrm{U} / \mathrm{ml}$ \\
\hline & & & Lupic anticoagulant & \multicolumn{2}{|c|}{ Negative } \\
\hline CMV IgG & 82.64 & $\mathrm{U} / \mathrm{ml}$ & Anti-phospholipid & \multicolumn{2}{|c|}{ Negative } \\
\hline CMV IgM & 0.14 & $\mathrm{U} / \mathrm{ml}$ & & & \\
\hline EBV IgG & 50.88 & $\mathrm{U} / \mathrm{ml}$ & D dimer & 1.06 & $\mathrm{ng} / \mathrm{ml}$ \\
\hline EBV IgM & 0.16 & $\mathrm{U} / \mathrm{ml}$ & VIII factor & 140.5 & $\mathrm{U} / \mathrm{dl}$ \\
\hline Enterovirus & \multicolumn{2}{|c|}{ Positive } & V factor (Leyden) & \multicolumn{2}{|c|}{ Negative } \\
\hline \multirow[t]{2}{*}{ Adenovirus } & \multicolumn{2}{|c|}{ Positive } & NRI & 0.93 & \\
\hline & & & Prothrombin & 20.8 & $\mathrm{~s}$ \\
\hline PCR & 1.78 & $\mathrm{mg} / \mathrm{L}$ & Thrombin & 10.2 & $\mathrm{~s}$ \\
\hline Procalcitonin & 0.25 & $\mathrm{ng} / \mathrm{L}$ & Fibrinogen & 312.93 & $\mathrm{md} / \mathrm{dl}$ \\
\hline IL-6 & $<2.00$ & $\mathrm{pg} / \mathrm{L}$ & Antithrombin III & 72 & $\mathrm{ug} / \mathrm{ml}$ \\
\hline DHL & 953 & $\mathrm{U} / \mathrm{L}$ & C protein & 120 & $\%$ \\
\hline \multirow[t]{2}{*}{ ESR } & $<10$ & $\mathrm{~mm} / \mathrm{h}$ & S protein & 100.6 & $\%$ \\
\hline & & & Alfa 2-antiplasmin & 142 & $\%$ \\
\hline
\end{tabular}

Table 1: Hematological workup.

WBC: White Blood Cell; ESR: Erythrocyte Sedimentation Rate; CMV: Cytomegalovirus; EBV: Epstein Barr Virus; IL: Interleukin; DHL: Dehydrogenase Lactate; iCa: Ionic Calcium; tCa: Total Calcium.

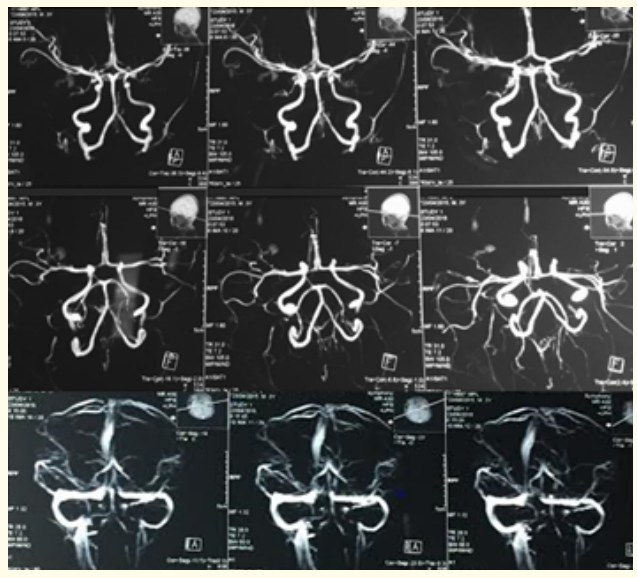

Figure 5: Angio MRI revealed neither occlusion nor stenosis of vessels on day 12 .

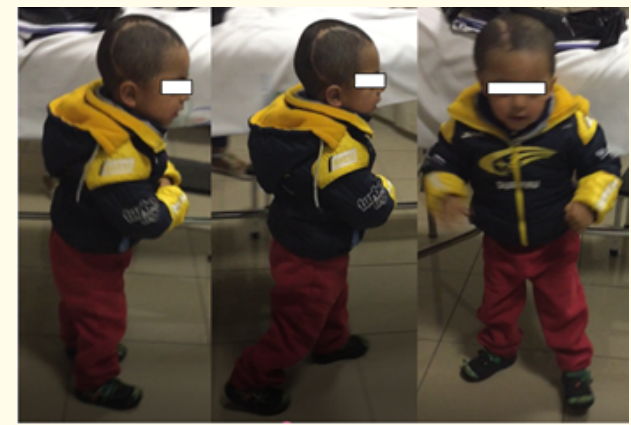

Figure 6: Follow-up with gradual neurological recovery.

\section{Discussion}

Mild head injuries are very common in childhood; however, stroke is an extremely rare sequel $[2,3,8]$. The pathophysiology of malignant stroke after mild head trauma in young children may be explained by any condition causing intimal damage which may 
cause subsequent thrombosis or vasospasm [3,8]. The relative delay of symptoms in most cases could be explained by the generation of thrombi and when immediate onset is seen, mechanical abrupt interruption of blood or spasm could explain it [8,9].

The nature of this entity and the reasons why this syndrome appears to be confined to young children remains unclear. The anatomical relationship between the lenticulostriate arteries and the trunk of the middle cerebral artery changes from fetal life to adulthood. Children may be more susceptible to movement, stretching and deformation even with mild trauma as the characteristics of the growing brain seem to play an important role $[2,5,6]$ and can influence dynamics between the fixed and mobile parts of the vessels $[5,6,9]$. The angle between the main trunk of the midbrain and the lenticulostriate arteries is acute in childhood (shorter segments) and becomes more obtuse with age, so even a slight impact on the skull would cause brain displacement with stretching and shearing effects on vessels due to high moment of inertia [2]. This would lead to endothelial intima injury and vessel dissection (e.g. dissecting aneurysm) with subsequent vasospasm and/or thrombosis $[1,2,3,5,6]$. Arterial dissection may account for up to $20 \%$ of cases of stroke in children and adolescents $[3,17]$.

Additionally, several histopathological studies have shown base ganglia calcifications related to some viral infections (Cytomegalovirus (CMV), Varicella Zoster). Calcium deposits in the mediumsized vessels without compromising the lumen, causing sclerosis, decreased flexibility, and stenosis [9]; thus, when calcifications exist, vasospasm and thrombosis are easier even with mild trauma [2,5]. Other Viruses such as chickenpox, Epstein Barr virus (EBV), ECHO virus, Influenza, and Parainfluenza virus $[5,10]$ have been pointed as well, but further research is suggested to establish causality. Enterovirus, adenovirus, and CMV tests were positive in our patient.

Some mutations for genetic susceptibility to arterial spasm or intimal alteration after trauma have also been described [11]. Malignant syndrome, a less frequent entity characterized by late cerebral edema and coma, has been informed in association with CANAIA (calcium channel subunits) gene mutation. This association suggests the possible role of genetic susceptibility $[6,9]$.

Traumatic vasospasm usually occurs after moderate to severe brain injury and could lead to cerebral ischemia. In pediatric patients, the typical time of appearance of the vasospasm peaks at days 2 to 3 and the duration is about 2 to 4 days which could explain events chronology described in our patient and its later imaging findings and neurological outcome as well $[2,12]$.
Up to $20 \%$ of children die after an ischemic brain event and $50 \%$ of those who survive have neurological sequelae according to the world registry. Mild trauma is an unusual mechanism of stroke in childhood and should be considered after excluding other causes [9]. Little research has been done on this topic $[8,13]$.

Mirvis., et al. [14] reported post-traumatic infarction in 25 (1.9\%) of 1,332 patients who required brain CT for trauma; posterior cerebral artery, anterior cerebral artery and middle cerebral arteries were the most frequently involved vessels. But our knowledge of post-traumatic malignant infarction due to occlusion of the middle cerebral artery is very limited.

Matsumoto., et al. [2] informed about 81 cases of cerebral infarction after minor head injury. They classified the resulting ischemic stroke into two types based on the affected vessel: typical type characterized by occlusion of a perforating artery (lateral lenticulostriate artery, Heubner artery, thalamogeniculate artery, or basilar perforating artery), and an atypical type characterized by occlusion of the distal internal carotid artery (ICA). Both tend to occur on the right side. Three cases in which ICA occlusion occurred after minor head injury predominantly affecting boys were highlighted. The ICA-type lesion is rarer and tends to affect older children $(>3$ years old) [2].

We report an atypical case of post-traumatic occlusion of the right middle cerebral artery (malignant infarct) after minor head trauma in a right-handed preschooler (3 years old) that required surgical management with primary hemispheric decompression $[2,5,15,16]$; good neurological recovery was achieved (Table 2). Most children with small post-traumatic infarctions make a full recovery after conservative therapy unless the brain stem is affected $[2,3,5]$. The rapid reversal or attenuation of neurological symptoms can be attributed to the resolution of the vasospasm. However, the healing process despite a stroke may be the result of infant neuronal plasticity [3].

\section{Conclusion}

Cerebral infarction after a minor head injury is an unusual mechanism of stroke in children and other possible causes should be ruled out before a diagnosis is formed $[3,5]$. It may be difficult to eliminate the possibility of an incident preceding and precipitating a head injury (seizures, black-out, etc.). In our case, the patient presented neurological signs after 48 hours of a fall witnessed by his mother. Furthermore, other possible morbidities which could cause vessel thrombosis were excluded by an extensive hematological workup. The reproducibility of the stroke pattern, the time relation with trauma, and therefore the exclusion of other stroke causes such as arterial dissection and cardiac sources of embolism, we conclude that this association is not accidental $[1,2,3,5,10]$. 


\begin{tabular}{|l|c|c|c|c|c|c|c|c|}
\hline \multicolumn{1}{|c|}{ Author } & Sex & Age (y) & Side & \multicolumn{2}{c|}{ Territory } & Mechanism & Treatment & Injury type \\
\hline Nakashima, 2001 [17] & M & 14 & Left & Frontal Lobe & Supraclinoid ICA & Dissection & Antiplatelets & Fall \\
\hline Matsumoto, 2011 [2] & M & 16 & Right & Frontal Lobe & Supraclinoid ICA & Vasospasm & STA-MCA bypass & Hit by pitch \\
\hline Current case & M & 3 & Right & Malignant & MCA & $\begin{array}{c}\text { Vasospasm vs } \\
\text { thrombi (?) }\end{array}$ & $\begin{array}{c}\text { Decompressive } \\
\text { craniectomy }\end{array}$ & \begin{tabular}{c} 
Fall \\
\hline
\end{tabular} \\
\hline
\end{tabular}

Table 2: Stroke ICA type after mild head trauma in childhood reported in literature*.

STA: Superficial Temporally Artery; MCA: Middle Cerebral Artery.

*One more case was reported by Ajir., et al [18]; however, it was removed from this table due to patient's age (18 years old).

In childhood, the most common risk factors for cerebrovascular events are congenital heart disease, sickle cell disease and various pro-thrombotic conditions. Recent studies highlight the importance of infections that appear to be related to at least a third of cases of cerebral ischemic events in children, especially in those with calcifications in the base ganglia (previous viral infections). Given the frequency of mild head trauma in children, the pathophysiology of cerebral infarction warrants future consideration [5]. Hospital admission, careful observation, and early diffusionweighted MRI should be considered in mild head trauma when neurological deficits persist [3].

\section{Acknowledgements}

We thank to Radiology Department of Carlos Andrade Marin Hospital for assistance with brain imaging.

\section{Conflict of Interest}

The authors declare that there is no conflict of interests regarding the publication of this paper.

\section{Bibliography}

1. Ahn JY., et al. "Posttraumatic Infarction in the Territory Supplied by the Lateral Lenticulostriate Artery after Minor Head Injury". Child's Nervous System 22.11 (2006):1493-1496.

2. Matsumoto H., et al. "Posttraumatic Cerebral Infarction Due to Progressive Occlusion of the Internal Carotid Artery after Minor Head Injury in Childhood: A Case Report". Child's Nervous System 27.7 (2011): 1169-1175.

3. Seçkin H., et al. "Posttraumatic Infarction in the Basal Ganglia after a Minor Head Injury in a Child: Case Report". Turkish Neurosurgery 18.4 (2008): 415-419.

4. Smith SE., et al. "Outcome Following Decompressive Craniectomy for Malignant Middle Cerebral Artery Infarction in Children". Developmental Medicine and Child Neurology 53.1 (2011): 29-33.

5. Yang FH., et al. "Cerebral Infarction after Mild Head Trauma in Children”. Indian Pediatrics 50.9 (2013): 875-878.
6. Rana KS., et al. "Ischemic Stroke Following Mild Head Injury: Is It the Cause?" Indian Pediatrics 43.11 (2006): 994-997.

7. Ciccone S., et al. "Ischemic Stroke in Infants and Children: Practical Management in Emergency". Stroke Research and Treatment (2011): 736965.

8. Yilmaz S., et al. "Post-Traumatic Cerebral Infarction: A Rare Complication in a Pediatric Patient after Mild Head Injury". Ulusal Travma ve Acil Cerrahi Dergisi 17.2 (2011): 186-188.

9. Shaffer L., et al. "Can mild head injury cause ischaemic stroke?" Archives of Disease in Childhood 88 (2003): 267-269.

10. Yang FH., et al. "Clinical Features and Risk Factors of Cerebral Infarction after Mild Head trauma under 18 Months of Age". Pediatric Neurology 48.3 (2013): 220-226.

11. Mastaglia FL. et al. "Intracranial thrombosis of the internal carotid artery after closed head injury". Journal of Neurology, Neurosurgery, and Psychiatry 32.5 (1969): 383-388.

12. Tsze DS., et al. "Pediatric Stroke: A Review". Emergency Medicine International (2011): 1-10.

13. Okuno T., et al. "Infarction of the internal capsule in children". Journal of Computer Assisted Tomography 4 (1980): 770-774.

14. Mirvis SE., et al. "Posttraumatic Cerebral Infarction Diagnosed by CT: Prevalence, Origin and Outcome". American Journal of Roentgenology 154.6 (1990): 1293-1298.

15. Ramaswamy V., et al. "Decompressive Hemicraniectomy in Children with Severe Ischemic Stroke and Life-Threatening Cerebral Edema". Journal of Child Neurology 23.8 (2008): 889894.

16. Shah S., et al. "Decompressive Hemicraniectomy in Pediatric Patients with Malignant Middle Cerebral Artery Infarction: Case Series and Review of the Literature". World Neurosurgery 80.1-2 (2013): 126-133. 
17. Nakashima S., et al. "Intracranial occlusion of the internal carotid artery after minor closed head injury". No to Shinkei 53.10 (2001): 975-978.

18. Ajir F., et al "Post-traumatic occlusion of the supraclinoid internal carotid artery”. Neurosurgery 9 (1981): 173-176.

Assets from publication with us

- Prompt Acknowledgement after receiving the article

- Thorough Double blinded peer review

- Rapid Publication

- Issue of Publication Certificate

- High visibility of your Published work

Website: www.actascientific.com/

Submit Article: www.actascientific.com/submission.php

Email us: editor@actascientific.com

Contact us: +91 9182824667 